\title{
Research of the path optimization in agricultural water-saving irrigation and canal system water distribution in Ant colony algorithm
}

\author{
Lei Lei DENG ${ }^{1}$, Zi Tong WANG ${ }^{1}$ \\ ${ }^{1}$ College of Information Technology, Ji lin Agricultural University ,Chang chun 130118
}

\begin{abstract}
To realize the management and control of the water-saving irrigation of the path pipeline distribution in field plots,get the terrain information through remote sensing technology and analyze the path and the amount of the water in the field plots by the ant colony algorithm according to the matter of the low generality in most parts in China.The result shows that the rules were put forward with shorter path,smaller cost and the most utilization of water eventually.It can be widely used in most areas which is lack of water and scientific technology.
\end{abstract}

Key word: ant colony algorithm,optimization of water allocation, pheromone ,water-saving irrigation

The ant colony algorithm was applied in saving data mining, network routing optimization, logistics distribution, and other issues as the development of the bionic engineering. The effect in agricultural irrigation has been known recently, therefore, how to design the Scientific and reasonable path and deployment plan is imperative.This article aimed to analyze several shorter path and distribution plans by the Positive feedback phenomenon of ant colony algorithm,by which the higher pheromone concentration the ants secret,the shorter path would be.According to the reasonable path,the aim to save water and increase production by using the Advanced science and technology can be reached.This research can provide new Ideas and methods for the 
implementation and management in water-saving irrigation with the data source in plot coordinates.

\section{1 methods and technology of} agricultural water-saving

\section{irrigation}

\subsection{Test plan}

This test is based on the field plot in Shuang Yashan,Hei Longjiang Province where the Regional differentiation is obvious, the land is trapezoidal orderly and the soil types are various that is suitable for the design of deployment of water-saving pipeline.Choose a coordinate point in the experimental plot area of the high terrain ,calculate the approximate optimal solution by the ant colony algorithm and then set the line path optimization.Soil moisture monitoring equipment uses the GPRS wireless communication mode and the lower soil can reach the humidity without the hydrovalve directly when the higher soil humidity is set. Relief map of Shuang Yashan is as shown in the figure.

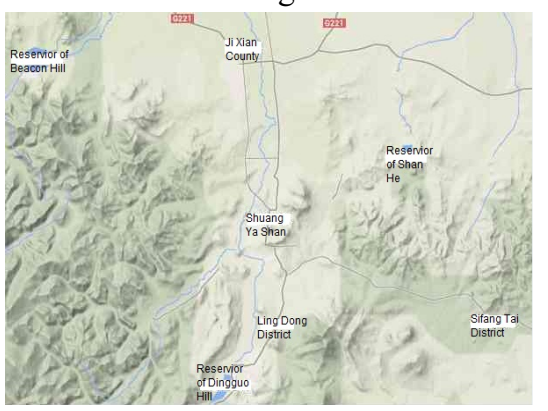

Figure 1.Relief map of Shuang Yashan

\subsection{Technology of the test}

The ant colony algorithm was raised connecting to the research of TSP, which was called the traveling businessman matter. It can be described that if a businessman would visit $\mathrm{n}$ cities, he must choose the corresponding path whose qualification is each city must be visited only once and when he return to the first city, the calculating distance is the shortest among all the tries.

This paper simulates the phenomenon of ants foraging and several mathematical symbols were brought to introduce easily.

$C$ is the collection of cities, and $C=(1,2, \ldots \ldots, \mathrm{n}) \cdot d_{i j}$ stands for the distance between two cities. $b_{i}(t)$ means the number of ants in city $i$ at $t$, let $m$ be the total number of ants,so $m=\sum_{i=1}^{n} b_{i}(t)$ means the amount of pheromone on $(\mathrm{i}, \mathrm{j}), \quad \mathrm{V} \tau_{i j}$ means the increment, $\mathrm{V} \tau_{i j}{ }^{k}$ means the pheromone of Number $\mathrm{K}$ ant on the way $\mathrm{i}$ to $\mathrm{j} . \rho$ is the residual factor, and make $\rho \in(0,1], L_{k}$ is the distance of Number K ant walks , $p_{i j}^{k}$ is the probability of the first $\mathrm{k}$ ant moving direction.

The initial state, $\tau_{i j}(0)=\tau_{0}, \tau_{0}$ is a constant, $\mathrm{V} \tau_{i j}=0$.The update of pheromone follows the principles: 


$$
\begin{gathered}
\tau_{i j}(t+n)=\rho \tau_{i j}(t)+\mathrm{V} \tau_{i j} \\
\mathrm{~V} \tau_{i j}=\sum_{k=1}^{n} \mathrm{~V} \tau_{i j}{ }^{k}
\end{gathered}
$$

This paper research the information increment of the $\mathrm{K}$ ant moves a cycle by the model of Ant-cycle,when the ants appear,the number is

$$
\mathrm{V} \tau_{i j}{ }^{k}(t)= \begin{cases}\frac{Q}{L_{k}} & \\ 0 & \text { else }\end{cases}
$$

The ants are controlled by directions of probabilities,we set the route at $\mathrm{t}$ as allowed $_{k}$, the tabu table is tabu $u_{k}$ There is allowed $_{k}=\{0,1, \ldots, n-1\}-$ tabu $_{k}$ 。 Construct the following probability expressions by introducing information stimulating factor and expect stimulating factor

$p_{i j}^{k}=\left\{\begin{array}{l}\frac{\left[\tau_{i j}(t)\right]^{\alpha}\left[\eta_{i j}(t)\right]^{\beta}}{\sum_{s \in \text { allowed }_{k}}\left[\tau_{i j}(t)\right]^{\alpha}\left[\eta_{i j}(t)\right]^{\beta}} \quad \text { if } j \in \text { allowed }_{k} \\ 0 \quad \text { else }\end{array}\right.$

Therefore,ant colony algorithm can make sure the action mode and path and get the process disorderly to orderly by the pheromone. $M$ ants start from a city,and then come to the next judging by (4) and put $t a b u_{k}$. The pheromone will be changed according to (1)(2)(3) and the change can affect the construction of (4).After the repeated cycle,the optimal solution will be put forward.

\section{The simulation test for water-saving irrigation}

\subsection{Inspection of field}

This paper selects some fields plots in Shuang Yashan as the coordinates. The specific coordinates are as followed.

$x=[1.67,1.41,3.54,3.29,4.41,7.01,7.98,1.99,2.98,4$.

$56,3.46,3.96,5.55,6.73,7.69]$.

$y=[5.5,4.32,6.01,7.68,0.75,1.00,3.21,1.11,7.01,2.8$

$7,3.87,5.42,3.00,3.134 .59]$.

The scatter diagram is shown in the figure.

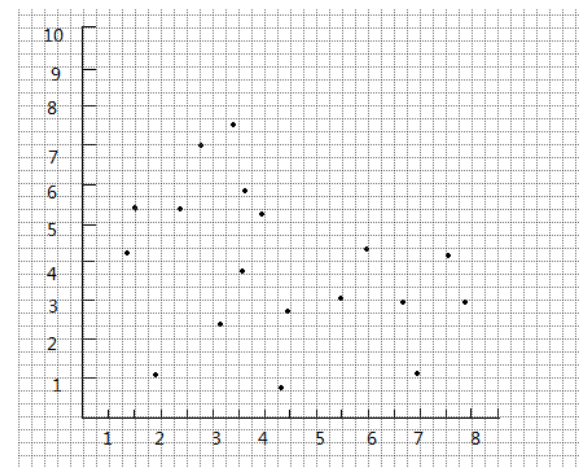

Figure2.The scatter diagram of the data

Calculate the processes and code them by Matlab,the route is

4-12-7-9-1-3-7-5-6-11-8-13-17-16-2-12-14-15-18, and the summation of them is

$$
\sum \operatorname{Dtao}(i j)=171
$$

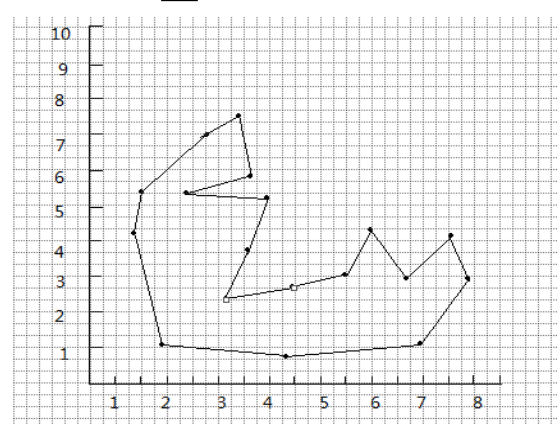

Figure 3.The path of the scatter 
This paper compares 3 irrigation methods with ant colony algorithm, make the conclusion of total irrigation water by irrigating in different times when the area is insured. The result shows that using the ant colony algorithm can save more water and the results of comparing shows in the figure.

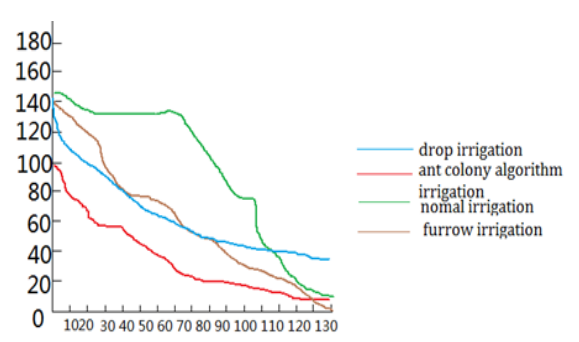

Figure4.different ways for irrigation

\begin{tabular}{|c|c|c|c|c|c|c|c|c|}
\hline \multirow[b]{2}{*}{$\begin{array}{l}\text { sequen } \\
\text { ce } \\
\text { numbe } \\
\text { I }\end{array}$} & \multirow[b]{2}{*}{$\begin{array}{c}\text { Total } \\
\text { areahm } \\
2 \\
v\end{array}$} & \multirow[b]{2}{*}{$\begin{array}{l}\text { Amount of } \\
\text { irrigation'm } \\
\text {, }\end{array}$} & \multicolumn{3}{|c|}{ vegettables } & \multicolumn{3}{|c|}{ apples } \\
\hline & & & 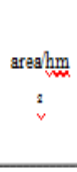 & $\begin{array}{l}\text { Amount of } \\
\text { need m' }\end{array}$ & $\begin{array}{c}\text { Average } \\
\text { of } \\
\text { quotam } \mathrm{m} \\
{ }^{2} \mathrm{hm}^{2}\end{array}$ & $\begin{array}{c}\text { areahm } \\
: \\
:\end{array}$ & $\begin{array}{l}\text { Amount of } \\
\text { need m' }\end{array}$ & $\begin{array}{c}\text { Average } \\
\text { of } \\
\text { quota } \mathrm{m}^{2} \text {. } \\
\mathrm{hm}^{2}\end{array}$ \\
\hline 1 & 167.18 & 155162.25 & 104.48 & 72927.00 & 600.25 & 62.69 & 82237.50 & 1128.15 \\
\hline 2 & 376.88 & 279546.75 & 235.55 & 152084.25 & 555.27 & 141.33 & 127462.50 & 775.63 \\
\hline 3 & 225.00 & 111125.25 & 140.63 & 85423.50 & 522.41 & 84.38 & 25701.75 & 261.97 \\
\hline 4 & 110.25 & 130977.00 & 68.91 & 32523.75 & 405.92 & 41.34 & 98453.25 & 2047.95 \\
\hline 5 & 358.43 & 341698.50 & 224.02 & 150347.25 & 577.19 & 134.41 & 191351.25 & 1224.33 \\
\hline 6 & 119.93 & 136356.75 & 74.95 & 35100.00 & 402.73 & 44.97 & 101256.75 & 1936.34 \\
\hline 7 & 368.10 & 201424.50 & 230.06 & 109570.50 & 409.59 & 138.04 & 91854.00 & 572.27 \\
\hline 8 & 112.50 & 71032.50 & 70.31 & 45742.50 & 559.48 & 42.19 & 25290.00 & 515.54 \\
\hline 9 & 408.83 & 214029.00 & 255.52 & 121997.25 & 410.61 & 153.31 & 92031.75 & 516.26 \\
\hline 10 & 378.90 & 306364.50 & 236.81 & 166657.50 & 605.23 & 142.09 & 139707.00 & 845.59 \\
\hline 11 & 636.08 & 614216.25 & 397.55 & 288681.75 & 624.50 & 238.53 & 325534.50 & 1173.70 \\
\hline 12 & 56.93 & 54045.00 & 35.58 & 23672.25 & 572.21 & 21.35 & 30150.00 & 1214.65 \\
\hline 13 & 326.25 & 383944.50 & 203.91 & 126702.00 & 534.38 & 122.34 & 257242.50 & 1808.25 \\
\hline 14 & 114.08 & 110479.50 & 71.30 & 41982.75 & 506.41 & 42.78 & 68496.75 & 1377.04 \\
\hline$\Sigma$ & 3759.30 & $\begin{array}{r}3110402.25 \\
\text { most }\end{array}$ & $\begin{array}{c}1283.04 \\
.\end{array}$ & 1453412.25 & $\begin{array}{l}7286.18 \\
\text { produl }\end{array}$ & $\begin{array}{l}2138.40 \\
\text { ct in }\end{array}$ & $\begin{array}{l}1656769.50 \\
\text { the }\end{array}$ & 662.99 \\
\hline
\end{tabular}

vegetables need $1453412.25 \mathrm{~m}^{3}$ while the apples need $1656769.50 \mathrm{~m}^{3}$.Although the area of apples is just as $60 \%$ as the vegetables,the water distribution tends to apples, that's because the apples are high economic crop.

\section{Conclusion}

This paper mainly takes out a method tending to get the most optimized result of only one path that can get to every point by using the ant colony algorithm.Meanwhile, the best effect of the way to water irrigation can be reached and the utilization of water is used in maximization. The method can solve the problems of serious water waste causing by uncertain path and low universalization of the deployment of canal water irrigation. It is 
worth to promote and employ especially in the areas where lack of water.

\section{References}

[1]LAN Y B, THOMSON S J, HUANG Y $\mathrm{B}$, et al. Computers and Electronics in Agriculture. Current status and future directions of precision aerial application for site - specific crop management in the USA $[\mathrm{J}]$. 34-38 , 7(2010).

[2]ZHU H, LAN Y B, WU W F, et al. Journal of Bionic Engineering. Development of a PWM precision spraying controller for unmanned aerial vehicles $[\mathrm{J}]$. 276-283, 7(2010).

[3] THOMSON S J, HUANG Y B,

HANKS J E, et al. Computers and Electronics in Agriculture. Improving flow response of a variable - rate aerial application system by interactive refinement [J].99-104. 73(2010).

[4] YU LI, LIANG MA.Journal of Shanghai University of science and technology.With quantum ant colony algorithm to solve the large-scale traveling salesman problem $[\mathrm{J}] .354$ $-358.34(2012)$..

[5] RINA S, YU W.Computer Engineering and Application.Quantum ant colony algorithm based on grid task scheduling research $[\mathrm{J}] .44$ -49.47(2011).

[6]WENCHUAN W,XIAOFENG L,DONGMEI $X$. China Rural Water and Hydropower. Large-scale water-saving reform comprehensive benefit evaluation method research[J].119123,1(2012).

[7]Fang Chong, Zhang Chunle, Lu Mingben. Water saving Irrigation .Application of TOPSIS method based on entropy weight coefficient in comprehensive evaluation of water saving reconstruction benefit in you irrigation $\operatorname{district}[\mathrm{J}]$. 52-54,2(2011).

[8] Yuan Yao, Liu Chao. Transactions of the Chinese Society for Agricultural Machinery. Pump operation optimization and projection pursuit evaluation strategy based on ant colony optimization[J]. 38-44. 44(2013). 